\title{
Melastomataceae no Parque Nacional do Itatiaia, Sudeste do Brasil: tribos Bertolonieae e Merianieae
}

\author{
Felipe Fajardo Villela A. Barberena ${ }^{1}$, José Fernando A. Baumgratz \& \\ Berenice Chiavegatto ${ }^{3}$
}

\begin{abstract}
Resumo
(Melastomataceae no Parque Nacional do Itatiaia, Sudeste do Brasil: tribos Bertolonieae e Merianieae) Realizou-se o estudo taxonômico de Melastomataceae, tribos Bertolonieae e Merianieae, no Parque Nacional do Itatiaia, situado entre os limites dos estados do Rio de Janeiro e Minas Gerais. Identificaram-se quatro espécies pertencentes a quatro gêneros - Bertolonia, Behuria, Huberia e Meriania. São apresentadas chaves analíticas para identificação de todos os gêneros ocorrentes no Parque e das espécies estudadas, bem como descrições, ilustrações, dados de distribuição geográfica e comentários sobre características morfológicas e particularidades do ambiente.
\end{abstract}

Palavras-chave: campos de altitude, flora, Mata Atlântica, taxonomia, Unidade de Conservação, florística.

\section{Abstract}

(Melastomataceae in the Itatiaia National Park, Southeastern Brazil: tribes Bertolonieae e Merianieae) The taxonomic study of the tribes Bertolonieae and Merianieae (Melastomataceae) in the Itatiaia National Park is presented. This conservation unit is located between Rio de Janeiro and Minas Gerais states, where one species of each Bertolonia, Behuria, Huberia and Meriania were found. Identification keys of all the Melastomataceae genera found within this area and for those species studied in detail are presented, accompanied by descriptions, illustrations, geographical distribution data and comments about morphological characteristics and habitat notes.

Key words: high altitude fields, flora, Atlantic Forest, taxonomy, Conservation Unit, floristics.

\section{INTRODUÇÃO}

As Melastomataceae figuram entre as famílias mais numerosas de Angiospermae e têm expressiva diversidade no estado do Rio de Janeiro, sendo estimados 27 gêneros e mais de 300 espécies, que são encontradas desde restingas até florestas pluviais alto-montanas, incluindo os campos de altitude (Baumgratz et al. 2006, 2007). Também para formações de Mata Atlântica tem sido apontada como uma família com significativa riqueza de espécies, alcançando liderança numérica em algumas regiões montanhosas (Rizzini 1954; Brade 1956; Martinelli et al. 1989; M.Lima \& Guedes-Bruni 1994; H.Lima \& Guedes-Bruni 1997; Baumgratz et al. 2006, 2007; Pereira et al. 2006).

Estudos florístico-taxonômicos sobre Melastomataceae na flora fluminense ainda são escassos e, nesse contexto, podem ser destacados os trabalhos de Brade (1956), Pereira (1961a, b, 1964, 1966) e Baumgratz (1980, 1982, 1984), mas que se mostram desatualizados e restritos a determinado município ou grupo taxonômico. Inventários florísticos também se mostram desatualizados ou específicos a determinadas áreas, apresentando listagens de espécies, comentários sobre particularidades morfológicas e ecológicas, indicação de ocorrência em Unidades de Conservação (UCs) e/ou documentação em coleções de herbários (Rizzini 1954; Brade 1956; Santos 1976; Oliveira et al. 1995; Baumgratz 1996, 1997a, b; Baumgratz et al. 2006, 2007; Pereira et al. 2006).

Nesse estado, embora remanescentes vegetacionais estejam bem preservados em UCs, as riquezas florísticas são ainda pouco conhecidas. Desse modo, inventários são prioritários nessas regiões, bem como estudos taxonômicos dos

Artigo recebido em 11/2007. Aceito para publicação em 03/2008.

1,2,3 Instituto de Pesquisas Jardim Botânico do Rio de Janeiro, R. Pacheco Leão 915, 22460-030, Rio de Janeiro, RJ, Brasil.

${ }^{1}$ Mestrando da Escola Nacional de Botânica Tropical/JBRJ. fbarbarena@ @brj.gov.br

${ }^{2}$ Pesquisador Titular; Bolsista de Produtividade CNPq. jbaumgra@jbrj.gov.br

${ }^{3}$ Doutoranda do JBRJ; Bolsista CAPES. berechiavegatto@jbrj.gov.br 
diversos grupos botânicos, principalmente daqueles numericamente expressivos, como as Melastomataceae (Baumgratz et al. 2006).

Várias dessas UCs abrangem regiões montanhosas das Serras do Mare da Mantiqueira, cujas formações florestais mais preservadas situam-se em elevadas altitudes e em áreas de difícil acesso. Florestas montanas ainda são desconhecidas e se mantêm entre as mais ameaçadas dos trópicos, além de haver importantes nascentes essenciais ao abastecimento hídrico e a fauna locais (Gentry 1995; Pereira et al. 2006).

O maciço do Itatiaia, situado na Serra da Mantiqueira, possui uma rica e densa cobertura florestal que vem sendo explorada por naturalistas brasileiros e estrangeiros desde séculos passados, possuindo uma rica flora arbórea na floresta ombrófila densa no Sudeste do Brasil (Pereira et al. 2006; Morim \& Barroso 2007). E exatamente nessa região, criou-se a primeira UC do Brasil, em 1937, o Parque Nacional do Itatiaia (PARNA Itatiaia). Nestes artigos, os autores assinalam que as florestas dessa unidade são ainda muito pouco conhecidas, o que estimula o desenvolvimento de novos estudos sobre a flora local.

Os primeiros dados sobre Melastomataceae no PARNA Itatiaia são apresentados por Dusén (1955) e Brade (1956) e se mostram importantes para a região, pois abordam a origem, estrutura e composição da flora de diferentes fitofisionomias, além de listarem e descreverem novas espécies. Por outro lado, informações recentes sobre essa família se restringem a estudos taxonômicos de revisão, como os de A.Martins (1989), Baumgratz (1990, 2004), E. Martins (1997), Guimarães (1997), Kloschsinske (1997), Souza (1998), Goldemberg (2000) e Tavares (2005). Já Martinelli et al. (1989), abordando os campos de altitude no Sudeste do Brasil, assinalam que Melastomataceae e Orchidaceae, no PARNA Itatiaia, são as famílias mais numerosas, depois de Asteraceae.

Recentemente, Pereira et al. (2006) ressaltam a importância dessa família como uma das mais numerosas em espécies no compartimento arbóreo de cinco remanescentes florestais do maciço do Itatiaia, além de Miconia e
Tibouchina serem os mais expressivos nessa região. Comentam que não só essa riqueza relativa de espécies como táxons destes dois gêneros e um de Trembleya têm sido considerados como indicadores de florestas atlânticas de maiores altitudes do Sudeste do Brasil e até mesmo do Neotrópico. Aspectos semelhantes da riqueza e importância de Melastomataceae em florestas andinas e nebulares são mencionados por Gentry (1995), Webster (1995) e Baumgratz et al. (2007).

Baumgratz (2007) aborda a diversidade taxonômica das Melastomataceae no PARNA Itatiaia, descrevendo, de modo geral, a distribuição do grupo nas fitofisionomias florestais e faixas altitudinais. Destaca a variada morfologia floral e frutífera, com inúmeras formas associadas a diferentes matizes de cores, constituindo importantes atributos dessas plantas no ecossistema local.

Desse modo, objetiva-se atualizar o conhecimento taxonômico dessa família no PARNA Itatiaia, abordando-se nesse trabalho quatro gêneros pertencentes a duas tribos Bertolonia (Bertolonieae) e Behuria, Huberia e Meriania (Merianieae). Apresenta-se uma chave analítica para identificação de todos os gêneros encontrados nessa UC e uma outra para o reconhecimento das quatro espécies estudadas, com descrições, ilustrações, dados de distribuição geográfica e particularidades destas espécies no ambiente. Além disso, espera-se contribuir para o conhecimento do grupo na flora do estado do Rio de Janeiro e fornecer subsídios para ações de conservação e recuperação de áreas nessa UC.

\section{Material e Métodos}

O PARNA Itatiaia, com uma área de ca. 30.000 ha, situa-se no sudoeste do estado do Rio de Janeiro, nos municípios de Resende e Itatiaia, e ao sul de Minas Gerais, em Itamonte e Bocaina de Minas. Integra a cadeia montanhosa e interiorana da Serra da Mantiqueira, no Maciço de Itatiaia, entre $816 \mathrm{~m}$ de altitude, na parte sul e com matas de encosta, até 2.787 m, nas partes mais acidentadas do relevo (Martinelli 1989; Morim 2006; Morim \& Barroso 2007). 
Integrado no domínio Mata Atlântica, constitui um centro de diversidade e endemismo no Neotrópico, estando representado por formações florestais e campestres, onde a família Melastomataceae tem sido destacada pela riqueza de espécies (Brade 1956; Martinelli 1989; Baumgratz 2007).

A vegetação no PARNA Itatiaia é caracterizada como do tipo Floresta Ombrófila Densa, sendo reconhecidas três formações com base na altitude: Submontana, Montana e Alto-montana ou mata nebular (Veloso et al. 1991). Nesta cota altitudinal destacam-se também os campos de altitude, pela peculiar fitofisionomia da paisagem com afloramentos rochosos, com base em Martinelli et al. (1989).

As características fisiográficas do PARNA Itatiaia citadas no texto baseiam-se no trabalho de Morim (2006).

Realizou-se o levantamento dos táxons em literatura, no herbário RB e nas bases de dados da Diretoria de Pesquisa Científica e do Programa Mata Atlântica (PMA), do JBRJ, cujos dados foram revistos pelos autores. As siglas dos herbários citadas no texto seguem Holmgren et al. (1990).

As circunscrições das tribos estudadas seguem Baumgratz et al. (2007), que se basearam nas proposições classificatórias de Renner (1993) e Clausing \& Renner (2001) para a família Melastomataceae.

Adotaram-se os conceitos de Radford et al. (1974) para as caracterizações morfológicas, de Baumgratz (1985), para tipificação dos frutos e formas das sementes, e de Veloso et al. (1991), para os tipos de vegetação.

Realizaram-se recentes expedições a campo, percorrendo-se diversas trilhas em diferentes altitudes e fitofisionomias para coleta de amostras férteis. Procederam-se técnicas usuais de herborização do material botânico e posterior inclusão dos exemplares no herbário RB. Amostras de partes vegetativas e florais também foram fixadas em álcool a 70\%, para análise em laboratório. $\mathrm{Na}$ análise das amostras e realização das ilustrações utilizou-se microscópio estereoscópio acoplado à câmara clara.

\section{Resultados e Discussão Melastomataceae Juss.}

Árvores, arbustos ou subarbustos, às vezes ervas ou epífitas. Indumento variado em partes vegetativas e florais, tricomas simples e ramificados, glandulares ou não. Folhas simples, decussadas, pecioladas; nervuras acródromas basais ou suprabasais. Inflorescências de tipos variados, terminais, axilares ou pseudo-axilares; brácteas e profilos freqüentemente presentes. Flores períginas a epíginas. Hipanto persistente, raro ausente na frutificação (Bertolonia); zona do disco glabra ou pilosa. Cálice de prefloração regular ou irregularmente valvar, persistente ou caduco. Corola de prefloração torcida, pétalas alvas, alvorosadas, lilases ou purpúreas, livres. Estames infletidos no botão floral, iguais ou desiguais na forma e/ou tamanho, anteras retilíneas ou curvas a falciformes, poricidas, às vezes poro prolongandose como uma rima, conectivo prolongado ou não abaixo das tecas, inapendiculado ou apêndice dorsal ou ventral. Ovário livre ou adnato ao hipanto, geralmente 3-5-locular, usualmente multiovulado, placentação axilar. Frutos carnosos (bacídios ou bacáceos) ou secos (cápsulas loculicidas, ruptídios, bertolonídios ou velatídios), polispérmicos ou oligospérmicos. Sementes obtriangulares, obovadas, ovadas ou cocleares, raro aladas.

\section{As tribos no PARNA Itatiaia}

O levantamento realizado na literatura e no herbário RB indica a ocorrência de 15 gêneros e cerca de 123 espécies de Melastomataceae no PARNA Itatiaia, destacando Leandra, Tibouchina e Miconia como os gêneros mais ricos em espécies e predominantes nas formações montanas. Esses táxons pertencem a cinco tribos, que, segundo Baumgratz et al. (2007), podem ser distintas por um conjunto de características morfológicas vegetativas, florais e frutíferas.

Bertolonieae Triana: Herbáceas. Inflorescências escorpióides. Estames dimórficos, subiguais em tamanho, com conectivo prolongado abaixo das tecas, inapendiculado ou com apêndice ventral ou dorsal. Frutos capsulares, obtriquetros. Sementes achatadas lateralmente, rostradas, não aladas, com testa tuberculada e papilosa. (Bertolonia - 1 sp.). 
Merianieae Triana: Estames dimórficos, desiguais ou de dois tamanhos, com conectivo geralmente não prolongado abaixo das tecas, às vezes inconspícuamente prolongado, com apêndice dorsal, raro inapendiculado. Frutos capsulares, nunca obtriquetras. Sementes achatadas dorsoventralmente ou lateralmente, obtriangulares, cuneadas, lineares, oblongas, elípticas ou obovadas, aladas ou não, raro rostradas, testa áspera a granulada. (Behuria, Huberia e Meriania 1 sp. cada).

Melastomeae L.: Estames dimórficos, de dois tamanhos, com o conectivo nitidamente prolongado abaixo das tecas, apêndice ventral. Frutos capsulares, nunca obtriquetros. Ovário com tricomas persistentes. Sementes levemente achatadas lateralmente, cocleares, às vezes oblongas e curvas para o ápice, não rostradas, com testa granulosa, papilosa, reticulada ou reticulado-foveolada. (Acisanthera - $1 \mathrm{sp}$; Trembleya - 3 spp.; Tibouchina - 34 spp.).
Miconieae DC.: Estames isomórficos ou subisomórficos, em geral iguais ou subiguais no tamanho, com conectivo curtamente ou não prolongado abaixo das tecas, inapendiculado ou com apêndice dorsal, formando ou não projeções ventrais. Frutos carnosos. Sementes freqüentemente obpiramidais, com testa papilosa, granulosa ou aparentemente psilada. (Clidemia - 3 spp.; Henriettella - 1 sp.; Leandra -40 spp.; Miconia-28 spp.; Ossaea-3 spp.).

Microlicieae Triana: Subarbustos a arbustos freqüentemente micrófilos. Estames dimórficos, de dois tamanhos, com o conectivo nitidamente prolongado abaixo das tecas, apêndice ventral. Ovário glabro ou piloso. Frutos capsulares, nunca obtriquetros. Sementes achatadas lateralmente, retilíneas a levemente curvas, oblongas ou ovadoobovadas, não rostradas, raro levemente aladas, testa foveolada. (Chaetostoma, Microlicia e Lavoisiera - 2 spp. cada).

\section{Chave para identificação dos gêneros de Melastomataceae no PARNA Itatiaia}

1. Cálice unilobado, laciniado ou raro truncado, neste caso, lacínias formando uma bainha sinuosa pós-antese, ou cálice inconspícuo-bilobado, irregularmente endenteado (lobos externos reduzidos a dentículos punctiformes ou mamilares); frutos capsulares.

2. Flores pentâmeras.

3. Folhas com nervuras paralelódromas; hipanto com uma série de emergências no ápice, abaixo das lacínias do cálice Chaetostoma

3'. Folhas com nervuras acródromas; hipanto sem essa característica.

4. Inflorescências em cimeiras escorpióides; cápsulas do tipo bertolonídio, obtriquetras Bertolonia

4'. Inflorescências de outros tipos, não de cimeiras escorpióides; cápsulas de outros tipos, nunca bertolonídios, oblongas, ovadas ou elípticas.

5. Lacínias do cálice inconspícuas, irregularmente endenteadas, formando uma bainha sinuosa; estames com apêndice do conectivo dorsal e a porção ascendente paralela à antera Meriania

5'. Lacínias do cálice distintamente desenvolvidas, denteadas; estames com apêndice do conectivo ventral.

6. Arbustos microfilos, cespitosos; indumento dos ramos glandulosogranuloso; folhas sésseis, nervuras acródromas de desenvolvimento imperfeito Microlicia

6'. Arbustos não microfilos nem cespitosos; indumento de outros tipos, não glanduloso-granuloso; folhas pecioladas, às vezes sésseis, nervuras acródromas de desenvolvimento perfeito. 
7. Anteras oblongas, retilíneas, ápice estreitado, curto-rostrado; sementes oblongas, curvas para o ápice .

7'. Anteras linear-subuladas, curvas a falciformes, ápice atenuado, não estreitado nem rostrado; sementes cocleares.

8. Estames com apêndice do conectivo bífido, projeções alongadas, digitiformes; ovário livre no interior do hipanto; cápsulas 3-valvares Acisanthera

8'. Estames com apêndice do conectivo bilobado a biauriculado; ovário parcialmente adnato ao hipanto; cápsulas 4-5-valvares. Tibouchina

2'. Flores tetrâmeras ou hexâmeras.

9. Arvoretas ou árvores; flores tetrâmeras; sementes achatadas dorso-ventralmente.. Huberia

9'. Subarbustos ou arbustos; flores hexâmeras; sementes achatadas lateralmente.

10. Flores reunidas em inflorescências; estames com apêndice do conectivo dorsal; cápsulas deiscentes do ápice para a base Behuria

10'. Flores solitárias; estames com apêndice do conectivo ventral; cápsulas deiscentes da base para o ápice Lavoisiera

1'. Cálice bilobado, laciniado (lobos externos geralmente conspícuos, às vezes inconspícuos ou obsoletos e reduzidos a dentículos, não punctiformes nem mamilares); frutos carnosos.

12. Inflorescências axilares, dispostas em nós folhosos e/ou áfilos, neste caso, geralmente ao longo das porções inferiores dos ramos.

13. Árvores; inflorescências fasciculadas; cálice truncado a levemente ondulado

Henriettella

13'. Arbustos; inflorescências não em fascículos; cálice distinto laciniado, não truncado nem ondulado

Ossaea

12'. Inflorescências terminais e/ou pseudo-axilares, raro axilares em nós folhosos das extremidades dos ramos.

14. Botões florais e pétalas de ápice agudo a acuminado (lobos externos do cálice maiores que os internos) Leandra

14'. Botões florais de ápice obtuso e/ou arredondado; pétalas com ápice arredondado ou assimetricamente emarginado ou retuso (lobos externos do cálice inconspícuos ou evidentes, neste caso, menores ou maiores que os internos).

15. Inflorescências terminais e pseudo-axilares, se também axilares, planta epífita; lobos externos do cálice maiores que os internos Clidemia

15'. Inflorescências freqüentemente terminais, às vezes axilares em nós folhosos das extremidades dos ramos e, neste caso, plantas arbóreas; lobos externos do cálice inconspícuos ou, se evidentes, menores que os internos Miconia

\section{As tribos Bertolonieae e Merianieae no PARNA Itatiaia}

Bertolonieae está representada apenas por Bertolonia mosenii, uma espécie encontrada em florestas úmidas das Regiões Sudeste e Sul do Brasil (Baumgratz 1990). Já Merianieae, representa-se por Behuria parvifolia, Huberia nettoana e Meriania claussenii, todas restritas à Região Sudeste. Enquanto a primeira espécie ocorre em campos de altitude, as demais são encontradas em formações florestais submontanas a altomontanas (Baumgratz 2004; Tavares 2005; Baumgratz et al. 2007). 


\section{Chave para identificação das espécies das tribos Merianieae e Bertolonieae no PARNA Itatiaia}

1. Ervas; inflorescências escorpióides

Bertolonia mosenii

1'. Arbustos, arvoretas ou árvores; inflorescências não escorpióides.

2. Folhas com 3 nervuras acródromas, domácias marsupiformes na face adaxial; flores 4meras; hipanto 8-costado Huberia nettoana

2'. Folhas com 5 nervuras acródromas, domácias ausentes; flores 5- ou 6-meras; hipanto não costado.

3. Arbustos; folhas de base arredondada; flores 6-meras

Behuria parvifolia

3'. Árvores; folhas de base aguda a cuneada ou atenuado-cuneada; flores 5-meras .....

Meriania claussenii

\section{DESCRIÇão DOS TÁXONS}

Bertolonia mosenii Cogn., in Mart. \& Eichl., Fl. bras. 14(4): 55. 1886.

Fig. 1 a-e

Ervas $0,1-0,3 \mathrm{~m}$ alt., terrestres, às vezes epífitas ou rupícolas; indumento dos ramos e face adaxial das folhas e profilos glanduloso-pontuado e esparsa a moderadamente setuloso, tricomas geralmente caducos. Folhas com pecíolo 0,6-4,5 cm; lâmina 2,6-8,5 × 1,5$5 \mathrm{~cm}$, discolor, face adaxial verde, abaxial vinosa, cartácea, ovada a elíptica, base e ápice agudos, margem serrada; 5 nervuras acródomas basais. Cimeiras escorpióides ou dicásios de cimeiras escorpióides 3,5-7 cm, terminais, pedunculadas; profilos presentes. Flores 5-meras; pedicelo 0,8-1,1 mm; hipanto 2-2,5 × 2,5-3,5 mm, campanulado, costado, desprovido de emergências no ápice; zona do disco papilosa; cálice unilobado, laciniado, tubo 0,4-0,5 mm, lacínias 0,4-1 ×0,6$0,8 \mathrm{~mm}$, eretas, triangulares a largamente ovadas, margem inteira a sinuosa; pétalas 6,5$7 \times 3 \mathrm{~mm}$, alvas, obovadas, ápice agudo, margem inteira, glabras; estames isomórficos, filetes 2,3-2,5 mm, anteras 1,5-2 mm, cremes, curvas, biporosas, poros dorsais, conectivo levemente prolongado, apêndice $0,3-0,4 \mathrm{~mm}$, dorsal, filiforme-subulado; ovário livre no interior do hipanto, ca. $2 \times 1,8-2 \mathrm{~mm}$, prolongamento apical trilobado, 3-locular, glabro; estilete ca. $5,5 \mathrm{~mm}$, alvo, pubescente-glanduloso na base; estigma capitado. Bertolonídios 4-7 × 4-9 mm, obtriquetras; sementes $0,5-0,8 \mathrm{~mm}$, achatadas lateralmente, obovadas, unilateralmente rostradas no ápice, testa tuberculada.
Material examinado: 13.XII.1935, fl. e fr., P. Campos Porto 2838 (RB); 25.II.1936, fl. e fr., A. C. Brade 15068 (RB); 13.I.1943, fl., J. J. Sampaio 1068 (RB); 15.II.1945, fl. e fr., A. C. Brade 17447 (RB); II.1948, fl. e fr., A. C. Brade s.n. (RB 62185); 28.IV.1962, fl., A. Castellanos 23369 (GUA); 15.IX.1994, fl. e fr., $R$. Guedes et al. 2477 (RB); 22.VI.1995, fl., J. M. Braga et al. 248 (RB); 8.XI.1995, fl., J. M. Braga et al. 2979 (RB); 6.II.2007, fr., J. F. A. Baumgratz et al. 913 (RB).

Ocorre em Minas Gerais, Rio de Janeiro, São Paulo, Paraná e Santa Catarina (Baumgratz 1990). No PARNA Itatiaia é encontrada entre 700 e $1.200 \mathrm{~m}$ de altitude, em floresta montana de encosta, em ambientes sombreados e úmidos geralmente próximos do rio Campo Belo, do Lago Azul e em trechos da trilha para cachoeira Itaporani. Brade (1956) assinala que essa espécie, na área de estudo, ocorre em mata higrófila subtropical.

Behuria parvifolia Cogn., in Mart. \& Eichl., Fl. bras. 14(4): 12-13, t. 2, fig. 2. 1886.

Fig. $1 \mathrm{f}-\mathrm{k}$

Arbustos ca. 1,5 m alt.; indumento glanduloso-pontuado e também setulosoglanduloso nos ramos, pedicelo, hipanto e cálice, tricomas caducos ou não, e pubescenteglanduloso nos pecíolos, face abaxial das folhas, hipanto e cálice. Folhas com pecíolo $0,2-0,5 \mathrm{~cm}$; lâmina $1,4-4 \times 0,5-2,3 \mathrm{~cm}$, cartácea, ovada a elíptica, base arredondada, ápice agudo a acuminado, margem serrada; 5 nervuras acródromas 1-1,5 mm suprabasais; domácias ausentes. Dicásios compostos 3,5$5,5 \mathrm{~cm}$, não escorpióides, terminais, pedunculados; brácteas e profilos presentes. Flores 6-meras; 


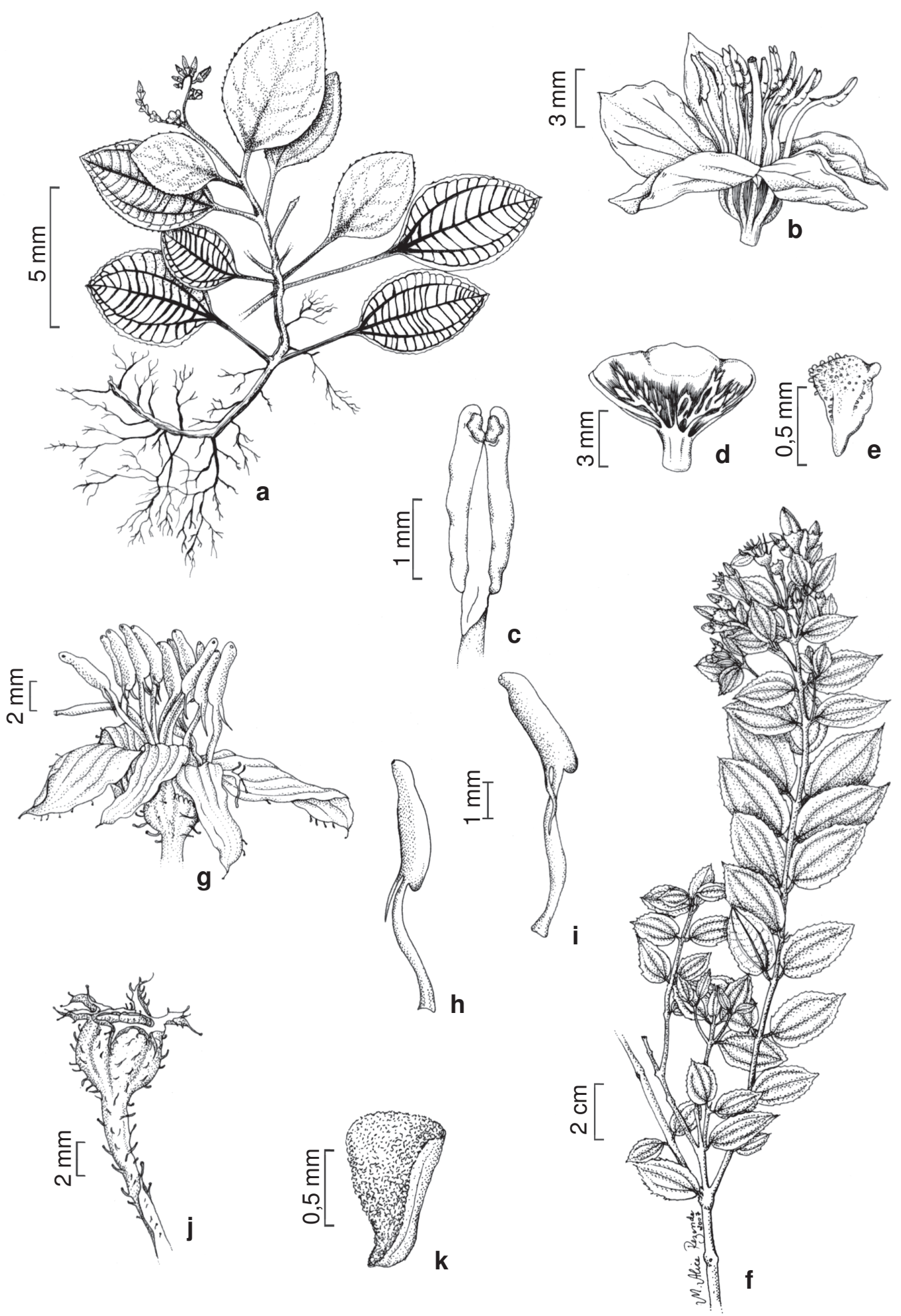

Figura 1 - Bertolonia mosenii Cogn. - a. hábito; b. flor; c. estame; d. bertolonídio; e. semente (Guedes 2477). Behuria parvifolia Cogn. - f. ramo florífero; g. flor; h-i. estames antepétalo e ante-sépalo, respectivamente; j. velatídio; k. semente (Eiten 6579). 
pedicelo 3-5 mm; hipanto ca. $3 \times 3,5-4 \mathrm{~mm}$, campanulado, não costado; zona do disco glabra; cálice unilobado, laciniado, tubo ca. $0,4 \mathrm{~mm}$, lacínias 1,5-3×0,5-0,8 mm, reflexas, triangulares, margem inteira; pétalas 10-11 × 3,5-4 mm, alvas, face dorsal rosada nos bordos, obovadas, ápice agudo, margem ciliado-glandulosa para o ápice; estames amarelos, subiguais em tamanho, filetes $7,5-9,8 \mathrm{~cm}$, anteras 3,2$4,3 \mathrm{~mm}$, oblongas, poro terminal, conectivo inconspicuamente prolongado, apêndice 2,5$3,2 \mathrm{~mm}$, dorsal, linear-subulado; ovário 2/3livres, 2-2,5×2-2,5 mm, 4-locular, pubescenteglanduloso; estilete 10-11 mm, alvo-amarelado. Velatídios 4-5 × 4-5,5 mm, globosos, polispérmicos; sementes $1-1,5 \mathrm{~mm}$, achatadas lateralmente, obtriangulares, aladas, alas estreitas, revolutas, testa áspera.

Material examinado: 27.XII.1895, fl. e fr., E. Ule s.n. (R 167042); 31.V.1902, fl., P. Dusen 409 (R); XI.1903, fl., C. Moreira 8 (R); 1915, fl., P. Campos Porto 183 (RB, SP); 31.I.1935, fl., P. Campos Porto 2720 (RB, US); 22-28.XI.1938, fl., F. Markgraf \& A. C. Brade 3711 (RB, US); 10.XII.1942, fl. e fr., E. Pereira s.n. (HB 6156); 23.VI.1943, fl. e fr., S. Vianna s.n. (RFA22995); XI.1952, fl. e fr., F. Markgraf \& A. C. Brade 21274 (NY, RB, US); 4.IX.1965, fl.e fr., G. Eiten et al. 6579 (K, SP, UB); 20.XI.1984, fl., V. F. Ferreira 3652 (GUA); 8.XI.1993, fl. e fr., R. Guedes et al. 2324 (RB).

Endêmica da Serra da Mantiqueira, ocorrendo nos estados do Rio de Janeiro, Minas Gerais e São Paulo, em florestas ombrófilas alto-montanas e em campos de altitude, entre 1.800-2.400 m de altitude (Tavares 2005). Foi recentemente coletada em mata nebular, a $1.790 \mathrm{~m}$ de altitude, na Serra do Ibitipoca, Minas Gerais, que integra o complexo da serra da Mantiqueira. Pode ser terrestre ou rupícola e no PARNA Itatiaia foi coletada na base do Pico das Agulhas Negras, Lagoa Bonita e em trechos da trilha entre Macieiras e Macena. Brade (1956) também assinala a ocorrência dessa espécie em campos abertos, acima de $2.000 \mathrm{~m}$ de altitude.

Tavares (2005) descreveu as folhas somente com forma elíptica, mas com base em um maior número de espécimes, pode-se observar que também são ovadas. Em relação aos estames, embora sejam subiguais em tamanho, dispõem-se de modo que os antesépalos são maiores que os antepétalos adjacentes.

Huberia nettoana Brade, Arch. Inst. Biol. Veg. 2(1): 13, est. 1, figs. 1-4. 1935.

Fig. 2 a-f

Arvoretas ou árvores 2-7 m alt.; indumento furfuráceo-glanduloso e, nas regiões intraxilares, viloso-glanduloso. Folhas com pecíolo 0,6-1,2 cm; lâmina 2,5-10 ×0,9-3 cm, papirácea, elíptica a oblonga, base agudo-decorrente ou curtodecorrente, ápice agudo a acuminado, margem inteira para a base e serrada para o ápice, ciliadoglandulosa; 3 nervuras acródromas 2-4 mm suprabasais; domácias marsupiformes, axilarprimárias, na face adaxial. Cimóides corimbosos 4-7 cm, não escorpióides, terminais, sésseis; brácteas e profilos presentes. Flores 4-meras; pedicelo 10-17 mm; hipanto $6,5-7 \times 2,8-3 \mathrm{~mm}$, campanulado, 8-costado; zona do disco glabra; cálice unilobado, laciniado, tubo 0,7-1 mm, lacínias 6-8 $\times 0,4-0,5 \mathrm{~mm}$, estreito-triangulares, margem inteira; pétalas 12,5-14×5-6 mm, alvas, ovadas, assimétricas, ápice agudo, margem inteira; estames de 2 tamanhos, anteras amarelas, curvas, poro ventral, conectivo não prolongado, com apêndice dorsal, linear-subulado, antesépalos com filetes $6-8,5 \mathrm{~mm}$, anteras 5-8 mm, conectivo com apêndice 1-2,5 mm, estames antepétalos com filetes 5-7 mm, anteras 4,5-7,5 $\mathrm{mm}$, conectivo com apêndices 1,5-2,5 mm; ovário 2/3-livres, 4,5-4,7×2-2,2 mm, 4-locular, glabro, ápice curtamente prolongado; estilete $6,5-13 \mathrm{~mm}$, alvo-amarelado, estigma capitado. Ruptídios 27$32 \times 7-11 \mathrm{~mm}$; sementes 5-6 mm, achatadas dorso-ventralmente, aladas, lineares a estreitamente obovadas ou ovadas.

Material examinado: 14.I.1936, fl. e fr., P. Campos Porto 2821 (RB); I.1939, fl., L. Lanstyak 256 (MO, NY, RB, US); 1.II.1965, fl., E. Pereira 9819 (F, HB, K, M); 31.I.1966, fl., S. Andrade 739 (RB); I.1987, fl., A. Salino 59 (SPF); 26.I.1994, fl. e fr., J. F. A. Baumgratz et al. 651, 652, 652A (FLOR, RB, SPF); 8.VIII.1996, fr., S. J. Silva Neto et al. 749 (RB); 6.II.2007, fl. e fr., J.F.A. Baumgratz et al. 923 (RB).

Ocorre nos estados de Minas Gerais, Rio de Janeiro e São Paulo, restrita às Serras do Mar e da Mantiqueira (Baumgratz 2004). Foi recentemente coletada em formação florestal 


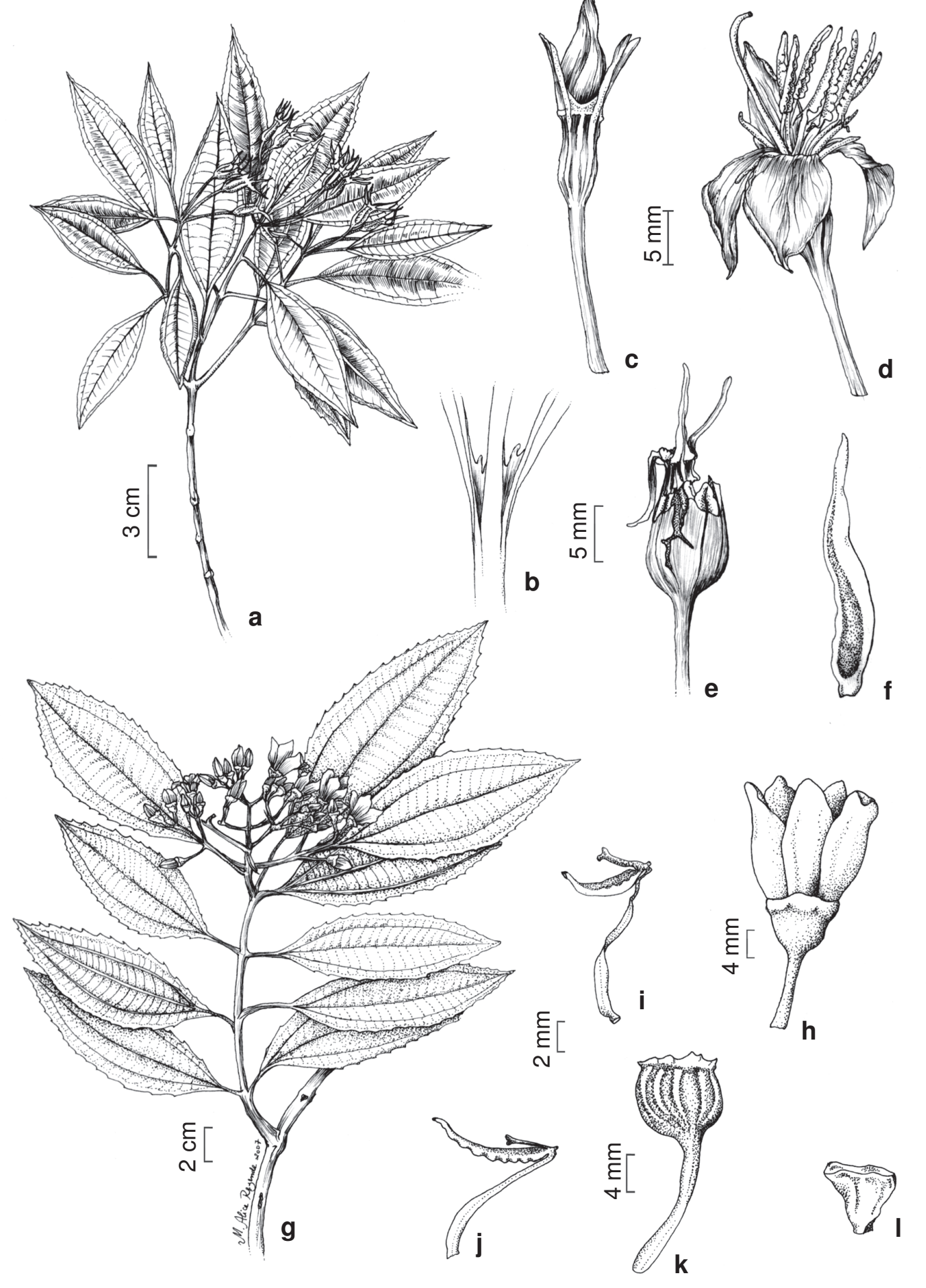

Figura 2 - Huberia nettoana Brade - a. ramo frutífero; b. detalhe da face abaxial da folha evidenciando a base agudodecorrente e as domácias; c. botão floral; d. flor; e. ruptídio; f. semente (Baumgratz 651). Meriania claussenii (Naudin) Triana - g. ramo florífero; h. flor; i-j. estames antepétalo e ante-sépalo, respectivamente; k. velatídio; 1 . semente (Andrade 516). 
de altitude na Serra do Ibitipoca, Minas Gerais, que integra o complexo da serra da Mantiqueira. No PARNA Itatiaia tem sido encontrada entre 1.600 a $2.300 \mathrm{~m}$ de altitude, em áreas da Serra Negra, Garganta do Registro e na estrada Registro para o Planalto, além de áreas alteradas por atividades antrópicas. Brade (1956) assinala a ocorrência dessa espécie tanto na Serra Negra quanto na porção noroeste do maciço.

Meriania claussenii (Naudin) Triana, Trans. Linn. Soc. Bot. 28(1): 66, tab.5, fig. 55i. 1871.

Fig. 2 g-1

Árvores 5-15 m alt.; indumento das folhas e inflorescências esparsamente dentrítico-furfuráceo, tricomas muito cedo caducos. Folhas com pecíolo $1,8-5,1 \mathrm{~cm}$; lâmina $8-13,7(-21) \times 3,8-5(-8,5) \mathrm{cm}$, rígidomembranácea, ovada a estreito-elíptica, base aguda a cuneada ou atenuado-cuneada, ápice agudo a acuminado, margem inteira para a base e serrada para o ápice, às vezes obscuroserrulada para o ápice; 5 nervuras acródromas, as mais internas $2-10 \mathrm{~mm}$ suprabasais; domácias ausentes. Tirsóides, cimóides de umbelas ou tríades, 5-7 cm, não escorpióides, terminais ou pseudo-axilares, pedunculados; brácteas e profilos presentes. Flores 5-meras; pedicelo 5-10 $\mathrm{mm}$; hipanto 4-4,2 $\mathrm{mm}$, campanulado, não costado, desprovido de emergências no ápice; zona do disco glabra; cálice inconspícuo-bilobado, irregularmente endenteado, formando uma bainha sinuosa, persistente, lacínias inconspícuas, lobos externos reduzidos a dentículos punctiformes ou mamilares; pétalas 4-16 ×7-9 mm, alvas, obovadas, ápice arredondado, margem inteira; estames desiguais em tamanho, filetes alvos, anteras linear-subuladas, extrorsamente curvas a falciformes, uniporadas, conectivo alaranjado, inconspicuamente prolongado, apêndice dorsal, porção ascendente paralela à antera, capitadobilobada, porção basal 0,2-0,4 mm, bilobulada, ante-sépalos com filetes 8-11 mm, anteras 3,5$5 \mathrm{~mm}$, roxo-lilases, poro terminal-ventral, porção ascendente do apêndice 2-2,5 mm, antepétalos com filetes $6,5-7,5 \mathrm{~mm}$, anteras $4,3-4,5 \mathrm{~mm}$, alvo-amareladas, poro dorsal, porção ascendente do apêndice ca. $3 \mathrm{~mm}$; ovário 2/3-livres, ca. $3,5 \times 3,5 \mathrm{~mm}$, róseo-lilás, 5-locular; estilete 5,5$11 \mathrm{~mm}$, alvo-lilás. Velatídios ca. 4-9×4-9 cm, oblongos; sementes $0,9-1,3 \mathrm{~mm}$, obtriangulares, às vezes rostradas, testa áspera a granulada. Material examinado: 1918, fl. e fr., P. Campos Porto 667 (RB); 18.VIII.1927, fr., P. Campos Porto 1549 (RB); 25.VI.1936, fl. e fr., P. Campos Porto 2931 \& L. Lanstyak 109(RB); 12.VII.1940, fl. efr., D. Ramos 5 (RB); 12.VIII.1947, fl. e fr., J. J. Sampaio 1185 (RB); 2.IX.1965, fl. e fr., S. Andrade 516 (RB); 15.IX.1994, fr., R. Guedes et al. 2475 (RB); 7.XII.1995, fr., J. M. A. Braga et al. 3078 (RB); 12.VIII.1997, fr., S. J. Silva Neto et al. 1212 (RB); 6.II.2007, fr., J. F. A. Baumgratz et al. 915 (RB); 11.IX.2007, fl. e fr., J. F. A. Baumgratz et al. 1001 (RB).

Restrita aos estados de Minas Gerais, Rio de Janeiro e São Paulo, ocorrendo em formações florestais montanas de encosta nas Serras do Mar e da Mantiqueira, entre 650 e $1.300 \mathrm{~m}$ de altitude. No PARNA Itatiaia é encontrada nas regiões da Maromba, Cachoeira Itaporani, Cachoeira Véu da Noiva, Vale do Taquaral, Rio Bonito, Mauá, Abrigo 3 e Lote 21. Encontrada no interior de mata, em ambientes úmidos e sombreados, raramente às margens de trilhas. Brade (1956) assinala a ocorrência dessa espécie nos trechos de matas secundárias mais antigas (os capoeirões).

Os estames são desiguais em tamanho, porém dispondo-se de modo que os ante-sépalos mostram-se maiores que os antepétalos adjacentes. Semelhante observação foi feita por Baumgratz et al. (2007), que estudaram essa espécie para a Reserva Ecológica de Macaé de Cima, no município de Nova Friburgo, RJ.

\section{Agradecimentos}

Ao CNPq e a CAPES, pelas Bolsas concedidas ao segundo e terceiro autores, respectivamente. A FAPERJ, pelo apoio à pesquisa concedido. Ao IBAMA e ao diretor do Parque Nacional do Itatiaia, pelo apoio, autorização de coleta e disponibilidade de infraestrutura. À ilustradora Maria Alice de Rezende, pela confecção das ilustrações. Aos Curadores dos herbários, pelo empréstimo de material e envio de fotografias ou imagens digitalizadas. 


\section{REFERÊNCIAS BIBLIOGRÁFICAS}

Baumgratz, J. F. A. 1980. Miconias do Município do Rio de Janeiro. Seção Miconia DC. (Melastomataceae). Rodriguésia 32(55): 73-95.

1982. Miconias do estado do Rio de Janeiro. Seção Tamonea (Aubl.) Cogniaux (Melastomataceae). Arquivos do Jardim Botânico do Rio Janeiro 26: 69-86.

1984. Miconias do estado do Rio de Janeiro. Seção Chaenanthera Naud. (Melastomataceae). Rodriguésia 36(60): 47-58.

1985. Morfologia dos frutos e sementes de Melastomataceae brasileiras. Arquivos do Jardim Botânico do Rio Janeiro 27: 113-155.

1990. O gênero Bertolonia Raddi

(Melastomataceae): revisão taxonômica e considerações anatômicas. Arquivos do Jardim Botânico do Rio Janeiro 30: 69-213. 1996. Melastomataceae. In: Marques, M. C. M. (org.). Espécies coletadas no Estado do Rio de Janeiro, depositadas no Herbário RB. Ed. Imprinta, Rio de Janeiro. Pp. 56-59.

1997a. Melastomataceae. In: Lima,

H. C. \& Guedes-Bruni, R. R. (eds.). Serra de Macaé de Cima: Diversidade Florística e Conservação em Mata Atlântica. Jardim Botânico do Rio de Janeiro, Rio de Janeiro. Pp. 331-332.

1997b. Melastomataceae. In: Marques,

M. C. M. (org.). Mapeamento da cobertura vegetal e listagem das espécies ocorrentes na Área de Proteção Ambiental de Cairuçu, Município de Parati, RJ. Série Estudos e Contribuições 13: 69-70.

2004. Sinopse de Huberia DC.

(Melastomataceae: Merianieae). Revista Brasileira de Botânica 27(3): 545-561. 2007. Melastomataceae-Diversidade de formas e cores na paisagem do Itatiaia. In: Teixeira, W. \& Linsker, R. (coords.). Itatiaia, sentinela das alturas. Terra Virgem Ed. (série Tempos do Brasil), São Paulo. Pp. 72-77.
; Souza, M. L. D. R.; Carraça, D. C. \& Abbas, B. A. 2006. Melastomataceae na Reserva Biológica de Poço das Antas, Silva Jardim, Rio de Janeiro, Brasil: aspectos florísticos e taxonômicos. Rodriguésia 57(3): 591-646.

; Souza, M. L. D. R. \& Tavares, R. A. M. 2007. Melastomataceae na Reserva Ecológica de Macaé de Cima, Nova Friburgo, Rio de Janeiro, Brasil. I - Tribos Bertolonieae, Merianieae e Micolicieae. Rodriguésia 58(4): 797-822.

Brade, A. C. 1956. A flora do Parque Nacional do Itatiaia. Boletim do Parque Nacional do Itatiaia 5: 7-85.

Clausing, G. \& Renner, S. S. 2001. Molecular phylogenetics of Melastomataceae and Memecylaceae: implications for character evolution. American Journal of Botany 88(3): 486-498.

Dusén, P. 1955. Contribuições para a Flora do Itatiaia. Boletim do Parque Nacional do Itatiaia 4: 9-91.

Gentry, A. H. 1995. Patterns of diversity and floristic composition in neotropical montane forests. In: Churchill, S. P.; Balslev, H.; Forero, E. \& Luteyn, J. L. (eds.). Biodiversity and Conservation of Neotropical Montane Forests: Proceedings of Neotropical Montane Forest Biodiversity and Conservation Symposium. The New York Botanical Garden, New York. Pp. 103-126.

Goldenberg, R. 2000. O gênero Miconia Ruiz \& Pav. (Melastomataceae): I. Listagens analíticas. II. Revisão taxonômica da seção Hypoxanthus (Rich. Ex DC.) Hook. f. Tese de Doutorado. Universidade Estadual de Campinas, Campinas, 249p.

Guimarães, P. J. F. 1997. Estudos taxonômicos de Tibouchina sect. Pleroma (D.Don) Cogn. (Melastomataceae). Tese de Doutorado. Universidade Estadual de Campinas, Campinas, 191p.

Holmgren, P. K.; Holmgren, N. H. \& Barnett, L. C. 1990. Index Herbariorum. Part I: The Herbaria of the world. Regnum vegetabile. New York Botanical Garden, New York, 8a ed., 693p. 
Kloschsinske, C. 1997. Revisão taxonômica do gênero Chaetostoma DC. (Melastomataceae). Tese de Doutorado. Universidade Estadual de Campinas, Campinas, 146p.

Lima, H. C. \& Guedes-Bruni, R. (eds.). 1997. Serra de Macaé de Cima: diversidade florística e conservação em Mata Atlântica. Jardim Botânico do Rio de Janeiro, Rio de Janeiro, 345p.

Lima, M. P. M. \& Guedes-Bruni, R. (orgs.). 1994. Reserva Ecológica de Macaé de Cima, Nova Friburgo, RJ: aspectos florísticos das espécies vasculares. Vol. 1. Jardim Botânico do Rio de Janeiro, IBGE, Divisão de Documentação e Processos Gráficos, Rio de Janeiro, 404p.

Martinelli, G.; Bandeira, J. \& Bragança, J. O. 1989. Campos de Altitude. Ed. Index, Rio de Janeiro, 160p.

Martins, A. B. 1989. Revisão taxonômica do gênero Marcetia DC. (Melastomataceae). Tese de Doutorado. Universidade Estadual de Campinas, Campinas, 275p.

Martins, E. 1997. Revisão taxonômica do gênero Trembleya DC. (Melastomataceae). Tese de Doutorado. Universidade Estadual de Campinas, Campinas, 162p.

Morim, M. P. 2006. Leguminosae arbustivas e arbóreas da floresta atlântica do Parque Nacional do Itatiaia, sudeste do Brasil: padrões de distribuição. Rodriguésia 57(1): $27-45$.

\& Barroso, G. M. 2007. Leguminosae arbustivas e arbóreas da floresta atlântica do Parque Nacional do Itatiaia, sudeste do Brasil: subfamílias Caesalpinioideae e Mimosoideae. Rodriguésia 58(2): 423-468.

Pereira, E. 1961a. Contribuição ao conhecimento das Melastomataceae brasileiras. Arquivos do Jardim Botânico do Rio Janeiro 17: 125-169.

1961b. Flora do estado da Guanabara III. Melastomataceae I - Tibouchineae. Rodriguésia 23-24 (35-36): 155-188.

. 1964. Flora do estado da Guanabara IV - Melastomataceae II. Miconieae.
Gênero Miconia. Arquivos do Jardim Botânico do Rio Janeiro 18: 183-214. 1966. Flora da Guanabara - V. Melastomataceae III (Final). Tribos: Miconieae, Merianieae, Bertolonieae e Microlicieae. Rodriguésia 25(37): 181-202.

Pereira, I. M.; Oliveira-Filho, A. T.; Botelho, S. A.; Carvalho, W. A. C.; Fontes, M. A. L.; Schiviani, I. Silva, A. F. 2006. Composição florística do compartimento arbóreo de cinco remanescentes florestais do maciço do Itatiaia, Minas Gerias e Rio de Janeiro. Rodriguésia 57(1): 103-126.

Radford, A. E.; Dickison, W. C.; Massey, J. R. \& Bell, C. R. 1974. Vascular plant systematics. Harper \& Row, New York, 891p.

Renner, S. S. 1993. Pylogeny and classification of the Melastomataceae and Memecylaceae. Nordic Journal of Botany 13(5): 519-540.

Rizzini, C. T. 1954. Flora Organensis. Lista preliminar dos Cormophyta da Serra dos Órgãos. Arquivos do Jardim Botânico do Rio Janeiro 13: 117-246.

Souza, M. L. D. R. 1998. Revisão taxonômica do gênero Ossaea DC. (Melastomataceae) no Brasil. Tese de Doutorado. Universidade de São Paulo, São Paulo, 317p.

Tavares, R. A. M. 2005. Revisão taxonômica do gênero Behuria Cham. (Melastomataceae). Dissertação de Mestrado. Universidade Federal do Rio de Janeiro, Rio de Janeiro, 202p.

Veloso, H. P.; Rangel Filho, A. L. R. \& Lima, J. C. A. 1991. Classificação da vegetação brasileira, adaptada a um sistema universal. Instituto Brasileiro de Geografia e Estatística. Rio de Janeiro, 116p.

Webster, G. L. 1995. The Panorama of Neotropical Cloud Forest. In: Churchill, S. P.; Balslev, H.; Forero, E. \& Luteyn, J. L. (eds.). Biodiversity and Conservation of Neotropical Montane Forests: Proceedings of Neotropical Montane Forest Biodiversity and Conservation Symposium. The New York Botanical Garden, New York. Pp. 53-77. 